\title{
PEMBUATAN ALAT UKUR SALINITAS DAN KEKERUHAN AIR MENGGUNAKAN SENSOR ELEKTRODA DAN LDR
}

\author{
Dina Mulya Siltri, Yohandri, Zulhendri Kamus \\ Jurusan Fisika FMIPA Universitas Negeri Padang \\ Jl. Prof. Hamka Air Tawar Barat Padang, 25171 \\ Email: dinamulya6@gmail.com
}

\begin{abstract}
The objective of this research is to determine both performance and design spesification of Salinitymeter and Turbiditymeter. This system combined from several sub systems such as electrode and Light Dependent Resistor (LDR) sensor, microcontroller Arduino, Liquid Crystal Display (LCD) and Light Emiting Diode (LED) indicators. The variable of this research are salinity and turbidity. The result of this research divided in two parts. The first is performance spesification, this system using copper electrode as salinity sensor and LDR as turbidity sensor. This consist of two plastic box which are circuit box and sample box. The second is design spesification that consist of some data such as accuration and precision. Salinity measurement has accuration $95.71 \%$ with precision $97.22 \%$, Turbidity measurement has $96.25 \%$ of accuration and 97.69\% of precision.
\end{abstract}

Key words: salinity, turbidity, electrode sensor

\section{PENDAHULUAN}

Air merupakan salah satu sumber daya alam (SDA) yang sangat dibutuhkan oleh manusia. Air berperan penting dalam menunjang kelangsungan hidup manusia seperti dibidang industri, pertanian, tempat umum dan konsumsi rumah tangga. Beberapa kebutuhan mendasar dalam kehidupan seperti minum, mencuci, memasak, mandi dan kakus sangat membutuhkan air. Segala upaya yang dilakukan manusia untuk bertahan hidup tidak akan berjalan dengan baik tanpa adanya air.

Air selalu tersedia di alam, namun tidak semua jenisnya bisa digunakan oleh manusia. Pemanfaatan air bersih untuk keperluan seharihari seperti untuk mandi, mencuci dan memasak harus memenuhi beberapa parameter air bersih diantaranya Total Dissolved Solid (TDS), suhu, daya hantar listrik (DHL), kadar garam (salinitas), bau, rasa, kekeruhan, kadar Clorida, $\mathrm{pH}$ dan kesadahan. Kadar salinitas dan kekeruhan menjadi salah satu hal yang penting diketahui agar tidak berdampak buruk kepada kesehatan manusia. Dua parameter ini dapat diukur dengan dua cara, yaitu secara analog dan digital.
Ada dua instrumen yang digunakan untuk mengukur kadar salinitas dan kekeruhan air secara digital yaitu Salinitymeter dan Turbiditymeter. Salinitymeter bekerja dengan menunjukan angka yang sesuai dengan salinitas air yang dideteksi oleh sensor. Selain itu, Turbiditymeter bekerja dengan membandingkan cahaya yang ditransmisikan dengan cahaya yang diterima oleh sensor yang ditempatkan $90^{\circ}$ terhadap sampel (HACH Company: 2008). Namun salinitymeter dan turbiditimeter yang ada pada saat ini memiliki harga yang mahal dalam pengoperasiannya. Di sisi lain, secara analog salinitas diukur menggunakan refraktometer. Refraktometer bekerja dengan prinsip pembiasan cahaya. Pembiasan cahaya akan terjadi apabila cahaya melewati dua medium yang memiliki kerapatan berbeda. Indeks bias pembiasan inilah yang nantinya akan dihitung sebagai salinitas (Sarah, 2005:2).

Berdasarkan latar belakang ini, penulis tertarik untuk membuat alat ukur salinitas dan kekeruhan sistem digital dengan alternatif yang lebih murah menggunakan sensor elektroda dan LDR. Pada sistem ini pengukuran kadar salinitas tidak lagi bergantung kepada cahaya, 
tetapi melalui kemampuan suatu larutan untuk menghantarkan arus listrik atau dikenal dengan istilah DHL. Kadar salinitas akan ditampilkan pada LCD dalam satuan permil $\left(\%_{0}\right)$. Selain itu, alat ini juga dilengkapi dengan LED sebagai indikator yang akan menunjukan jenis air berdasarkan salinitasnya, yaitu air tawar, air payau, air laut dan air pahit. Air segar ditandai dengan LED putih, air payau ditandai dengan LED hijau, air laut ditandai dengan LED kuning dan air yang sangat asin dan terasa pahit ditandai dengan LED merah. Di sisi lain, kekeruhan air diukur dengan mengukur banyaknya cahaya yang diterima oleh sensor LDR. Sumber cahaya yang digunakan adalah LED. Sebagian cahaya yang dipancarkan oleh LED akan dibelokkan dan sebagian lagi akan diteruskan berdasarkan partikel-partikel yang ada di dalam air. Cahaya yang dibelokkan ini akan diterima oleh LDR dan perubahan resistansi LDR ini menyebabkan perubahan tegangan keluaran pada rangkaian sensor LDR. Perubahan inilah yang akan diolah dan dikonversi dalam satuan kekeruhan yaitu Nephelometric Turbidity Units (NTU).

DHL merupakan kemampuan suatu cairan untuk menghantarkan arus listrik yang dikenal juga dengan istilah konduktivitas. Apabila antara dua buah elektroda diberi sebuah beda potensial, maka ion-ion yang ada di dalam air berpisah menjadi kation dan anion. Kation akan bergerak menuju elektroda negatif dan anion akan bergerak menuju elektroda positif. Ion-ion yang bergerak ini menyebabkan larutan bertindak sebagai konduktor (Radiometer
Analytical, 2004:5). Nilai DHL sebanding dengan kadar salinitas, semakin tinggi nilai DHL maka kadar salinitas pada larutan juga semakin tinggi.

Menurut Lewis (1986:6), salinitas praktis dari suatu perairan ditetapkan sebagai rasio dari konduktivitas listrik (K) air laut dan tekanan standar $1 \mathrm{~atm}$ terhadap larutan Kalium. Salinitas adalah konsentrasi seluruh larutan garam dan ion-ion yang terdapat dalam air laut. Komposisi ion-ion dalam air didominasi oleh klorida, karbonat, bikarbonat, sulfat, natrium, kalsium dan magnesium. Kandungan ion-iom dan konsentrasi garam-garam pada setiap air laut relatif sama. kadar salinitas dipengaruhi oleh beberapa faktor yaitu suhu, penguapan, curah hujan dan konsentrasi zat terlarut maupun pelarut yang terkandung dalam air.

Sensor salinitas merupakan salah satu sensor kimia yang dirancang berdasarkan sifat kelistrikan air. Resistansi pada air akan berkurang seiring dengan bertambahnya kadar garam. Sensor salinitas terdiri dari dua buah elektroda yang dicelupkan ke dalam air. Sensor diberi sebuah beda potensial agar terjadi aliran elektron pada rangkaian pembangun sensor. Elektroda diserikan dengan sebuah resistor variabel yang membentuk hubungan rangkaian pembagi tegangan. Tegangan keluaran sensor elektroda diukur pada terminal $\mathrm{AB}$ seperti yang tampak pada Gambar 1, kemudian data ini akan dikirim ke Arduino. Rangkaian dan ilustrasi sensor elektroda untuk mengukur salinitas dapat dilihat pada Gambar 1.

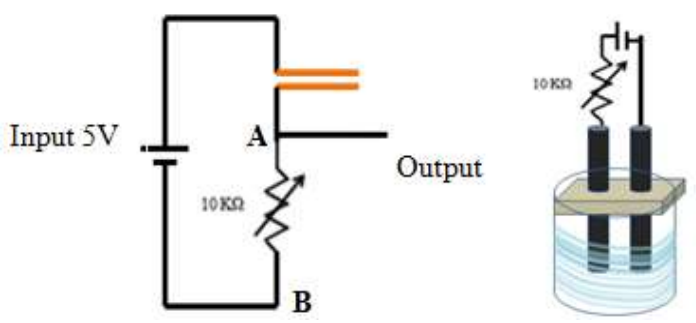

Gambar 1. Ilustrasi rangkaian sensor salinitas

Apabila elektroda dicelupkan kedalam air, maka rangkaian pada Gambar 1 akan menjadi sebuah rangkaian tertutup. Hal ini menyebabkan ion-ion dalam air akan terbebas.
Ion-ion pada air akan menghantarkan arus listrik sehingga tegangan pada terminal $\mathrm{AB}$ dapat dibaca.

Kekeruhan atau turbiditas merupakan salah satu sifat optik air. Sifat ini ditentukan 
berdasarkan daya tembus cahaya terhadap suatu larutan. Hal ini disebabkan sebagian cahaya matahari yang masuk ke dalam air akan terhambat oleh partikel-partikel dan kandungan organik dan anorganik yang ada di dalam perairan. Air dengan kekeruhan yang tinggi memiliki daya tembus cahaya matahari rendah.

Tingkat kekeruhan air dapat diukur menggunakan Turbiditymeter dalam skala NTU. Menurut Peraturan Menteri Kesehatan no 416/MENKES/PER/IX/1990. kadar kekeruhan maksimum untuk air minum adalah 5 NTU, sedangkan untuk air bersih kadar maksimum yang diperbolehkan adalah 25 NTU. Di sisi lain untuk budidaya kadar kekeruhan air maksimumnya adalah 30 NTU.
LDR digunakan untuk mendeteksi kekeruhan air. Partikel-partikel yang terlarut dalam air akan mengakibatkan cahaya yang dipancarkan oleh LED tidak sepenuhnya diterima oleh LDR. Cahaya tersebut terhambat oleh partikel-partikel halus yang berada dalam air sehingga hanya sebagian cahaya diteruskan dan sisanya akan dipantulkan dalam sudut $90^{\circ}$ kepada LDR terhadap sumber cahaya. Hal ini menyebabkan resistansi LDR menjadi lebih besar dari semula, sehingga tegangan keluaran sensor LDR semakin kecil. Rangkaian aplikasi sensor LDR untuk mendeteksi kekeruhan dapa dilihat pada Gambar 2.

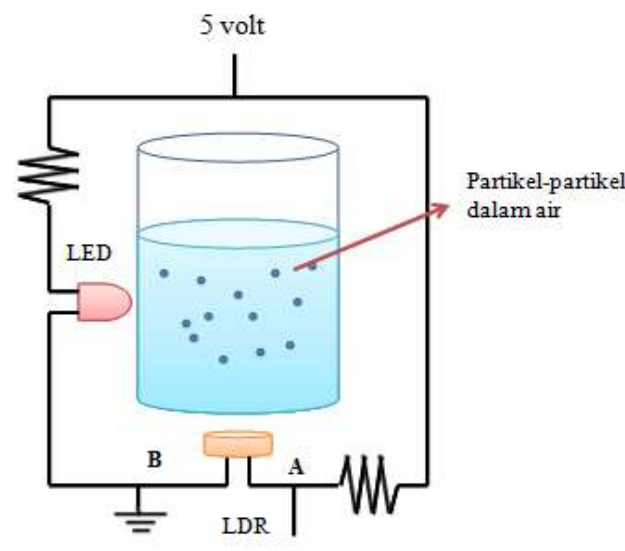

Gambar 2. Rangkaian aplikasi sensor kekeruhan

Pada Gambar 2 dapat dilihat bahwa pada LDR dipasang sebuah rangkaian pembagi tegangan, di mana tegangan keluaran pada rangkaian diukur pada terminal AB. Data tegangan keluaran inilah yang akan dimasukkan ke pin A1 pada arduino. Data ini selanjutnya akan diolah di Arduino dan ditampilkan pada LCD.

\section{METODE PENELITIAN}

Pada penelitian ini terdapat tiga variabel yaitu variabel bebas yang besarnya dapat diubah-ubah, variabel terikat yang besarnya tergantung pada variabel bebas dan variabel kontrol yang nilainya telah ditetapkan. Pada sistem alat ukur salinitas dan kekeruhan, sebagai variabel bebasnya kadar salinitas dan kekeruhan. DHL dan kekeruhan merupakan variabel terikat, sedangkan untuk variabel kontrol adalah nilai-nilai dari komponen elektronika yang digunakan.

\section{Desain Perangkat Keras}

Sistem ini terdiri dari catu daya $5 \mathrm{~V}$, sensor elektroda, LED, LDR, rangkaian mikrokontroler Arduino Uno328, indikator dan LCD. Catu daya berfungsi untuk mengaktifkan seluruh sistem alat ukur. LED digunakan sebagai sumber cahaya LDR. Selain itu indikator digunakan untuk menunjukan jenis air. Blok diagram alat ukur kadar salinitas dan kekeruhan dapat dilihat pada Gambar 3. 


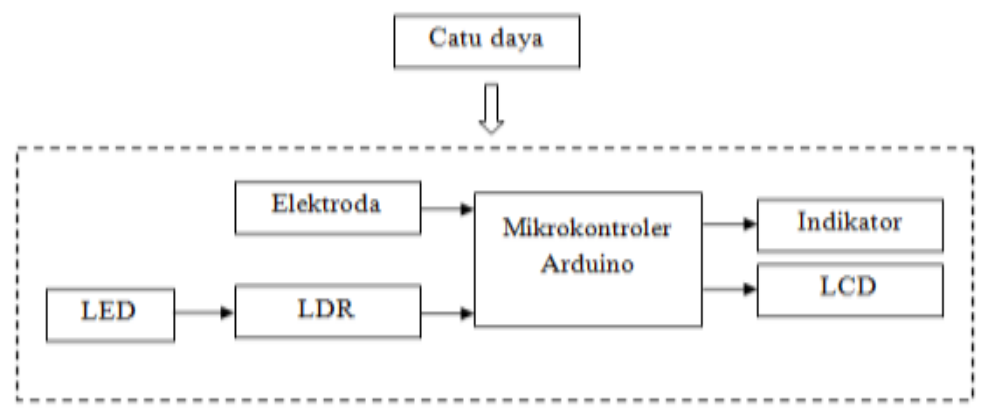

Gambar 3. Blok diagram alat ukur salinitas dan kekeruhan.

Dari Gambar 3 dapat dilihat bahwa tahap awal yaitu catu daya mengaktifkan seluruh sistem alat ukur. Tahap berikutnya sensor elektroda dan LDR mengukur salinitas dan kekeruhan sampel. Data yang diperoleh dari sensor kemudian dikirim ke Arduino. Arduino akan menerima dan mengolah data tersebut untuk ditampilkan pada LCD dan LED indikator. Ada empat LED indikator yang digunakan yaitu putih yang menandakan air tawar, LED hijau menandakan air payau, LED kuning menandakan air laut dan LED merah yang menjadi indikator air dalam kategori pahit.
Desain mekanik alat ukur kadar salinitas dan kekeruhan air terdiri dari sebuah kotak pengukuran. Kotak ini berukuran 15 x 26 x 25 $\mathrm{cm}$. Pada bagian atas kotak sengaja dilubangi dengan diameter $4 \mathrm{~cm}$ sebagai penahan sensor salinitas. Di dalam kotak terdapat dudukan untuk meletakkan sampel yang telah dimasukkan ke dalam gelas beker. Pada sisi kiri dudukan dipasang LED sebagai sumber cahaya, sedangkan LDR diletakkann di bawah dudukan sampel. Desain mekanik alat ukur seperti yang terlihat pada Gambar 4.

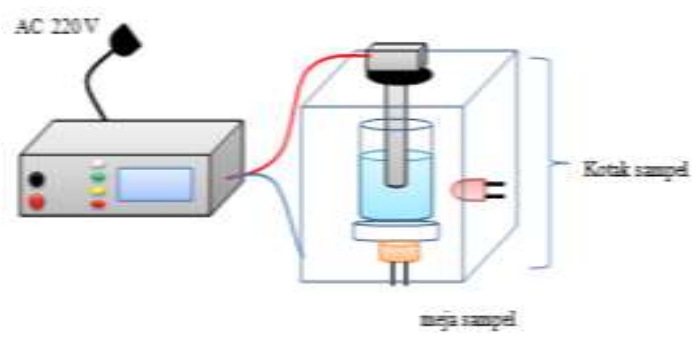

Gambar 4. Desain mekanik sistem alat ukur salinitas dan kekeruhan

Box rangkaian sebelah kanan Gambar 4 berisi semua rangkaian pendukung sistem alat dengan dimensi $25 \times 19,5 \times 7,5 \mathrm{~cm}$. Box ini terdiri dari 2 tombol yaitu tombol hitam yang berfungsi sebagai tombol on/off dan tombol merah yang berfungsi sebagai tombol reset.
Pada kotak terdapat deretan LED sebagai indikator dan LCD untuk menampilkan data kadar salinitias dan kekeruhan air yang telah diukur. 


\section{Desain Perangkat Lunak}

Perangkat lunak biasanya berfungsi untuk memberikan instruksi dan menjalankan program, pada sistem mikrokontroler biasa juga disebut firmware mikrokontroler. Instruksi yang dilakukan adalah untuk mengambil informasi salinitas dan kekeruhan, kemudian diolah pada mikrokontroler. Bahasa pemrograman yang digunakan adalah bahasa C. Compiler Arduino.

Tahap awal yang dilakukan program ketika catu daya diaktifkan adalah inisialisasi setiap variabel dan konstanta pin-pin yang digunakan dalam proses pengukuran. Kemudian judul akan ditampilkan pada LCD dan dilanjutkan oleh pembacaan data oleh sensor salinitas dan kekeruhan. Data yang diterima akan dikirim dan diolah di mikrokontroler dan kemudian ditampilkan pada LCD. Selain itu, untuk jenis air berdasarkan kadar salinitas juga diisyaratkan dengan 4 buah LED indikator yang akan diset high atau diberi logika "1" apabila memenuhi nilai salinitas yang telah ditentukan. LED putih akan menyala jika tegangan keluaran sensor salinitas kecil dari 2,7 $\mathrm{V}$, hal ini menandakan bahwa air yang diuji berada dalam kategori air tawar dengan salinitas kecil dari $0,5 \%$ o. Apabila tegangan keluaran sensor berada pada tegangan besar dari 2,7 dan kecil dari 3,11 maka yang menyala adalah LED hijau yang menandakan air payau dengan salinitas 5-30 \% . LED kuning menyala jika tegangan keluaran sensor salinitas berkisar antara $3,12 \mathrm{~V}$ dan $3,3 \mathrm{~V}$ dengan salinitas 31$50 \%$. Hal ini juga berlaku pada LED merah yang akan menyala jika tegangan keluaran sensor besar dari 3,3 V jika salinitas besar dari $50 \%$.

Hal pertama yang harus dilakukan untuk menentukan ketepatan yaitu menentukan persen kesalahan, rumus dari persen kesalahan dapat dilihat pada persamaan 1 :

persen kesalahan $=\frac{Y_{n}-X_{n}}{Y_{n}} \boldsymbol{x} \mathbf{1 0 0} \%$

dimana $:$ Yn $=$ Nilai sebenarnya dan Xn $=$ Nilai yang terbaca pada alat ukur.

Ketepatan pengukuran dari suatu sistem pengukuran dapat ditentukan melalui Persamaan :

$A=1-\left|\frac{Y_{n}-x_{n}}{Y_{n}}\right|$
Ketepatan relatif rata-rata dari sistem pengukuran dapat ditentukan melalui Persamaan:

$\% A=1-\left|\frac{Y_{n}-x_{n}}{Y_{n}}\right| x \mathbf{1 0 0} \%$

Hasil pengukuran dinyatakan dalam $X \pm \Delta X$ kemudian dapat ditentukan nilai rata-rata, standar deviasi, kesalahan mutlak dan relatif serta pelaporan hasil pengukuran. Nilai rata-rata pengukuran dinyatakan dengan

$\bar{X}=\frac{1}{n} \sum_{n=1}^{n} X_{n}$

(4)

Xn adalah nilai dari data ke-n dan jumlah jumlah total pengukuran dilambangkan dengan n. Ketelitian dapat diekspresikan dalam bentuk matematika sebagai berikut:

Precision $=1-\left|\frac{X_{n}-\bar{X}}{\bar{X}}\right|$

$\mathrm{Xn}$ adalah nilai dari data ke-n dan $\mathrm{n}$ adalah jumlah total pengukuran.Untuk mengukur standar deviasi dapat digunakan Persamaan:

$\Delta X=\frac{1}{n} \sqrt{\frac{n \sum X_{i}^{2}-\left(\sum X_{i}\right)^{2}}{n-1}}$

Dari hasil pengukuran dapat dilihat seberapa besar kesalahan relatif pengukuran pada alat dengan menggunakan Persamaan:

$K R=\frac{\Delta X}{\bar{X}} x 100 \%$

\section{HASIL DAN PEMBAHASAN}

Hasil penelitian diperoleh dengan melakukan identifikasi data yang meliputi pengaruh panambahan kadar garam dalam air terhadap tegangan keluaran sensor salinitas dan pengaruh variasi kekeruhan terhadap tegangan keluaran LDR. Data ini kemudian diolah dan dianallisis dengan membandingkan data yang diperoleh dengan alat ukur standar (AUS) dan data yang diperoleh dari alat ukur yang dibuat (AUD). Data disajikan dalam bentuk tabel dan grafik.

\section{Spesifikasi performansi Sistem}

Sensor salinitias terdiri dari dua buah elektroda tembaga yang memiliki panjang 23 $\mathrm{cm}$ dan diameter $3 \mathrm{~mm}$. Tembaga dipisahkan dengan jarak 2,5 cm di dalam pipa PVC 3/4". Bentuk fisik dari sensor salinitas dapat dilihat pada Gambar 5. 


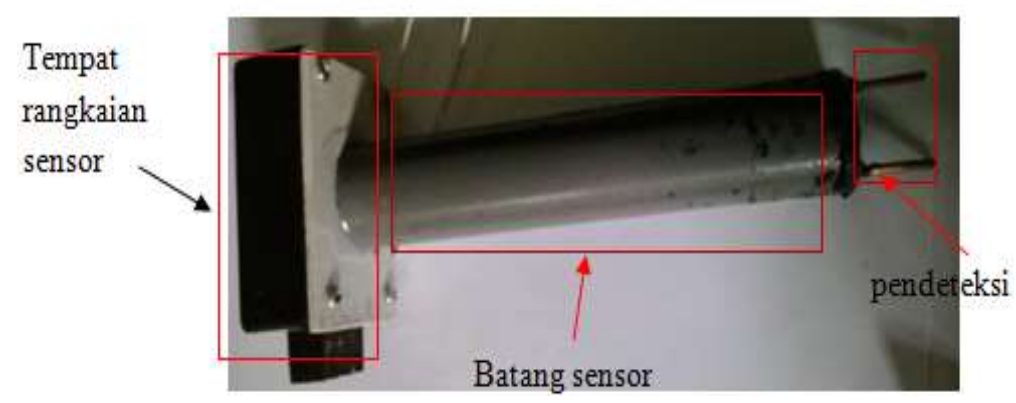

Gambar 5. Sensor salinitas

Secara keseluruhan sensor salinitas terdiri dari tiga bagian yaitu kepala, batang dan pendeteksi. Kepala sensor berupa sebuah kotak yang berisi rangkaian sensor, batang sensor berupa tabung yang terbuat dari pipa dan berfungsi menghubungkan antara bagian kepala dan pendeteksi. Selain itu bagian pendeteksi yang akan mengukur salinitas dengan cara dicelupkan ke dalam air.

Sistem mekanik pembentuk alat ukur terdiri atas dua bagian. Bagian pertama yaitu kotak sampel yang terbuat dari akrilik yang berukuran $15 \times 26 \times 25 \mathrm{~cm}$. pada bagian atas kotak dilubangi dengan diameter $4 \mathrm{~cm}$ untuk tempat sensor salinitas. Rancangan kotak sampel ini dapat dilhat pada Gambar 6 .

Sampel air akan dimasukkan ke dalam gelas beker $250 \mathrm{ml}$. Pada bagian dasar kotak ada dudukan sampel untuk meletakkan sampel. Bentuk dudukan sampel ini dapat dilihat pada Gambar 7.

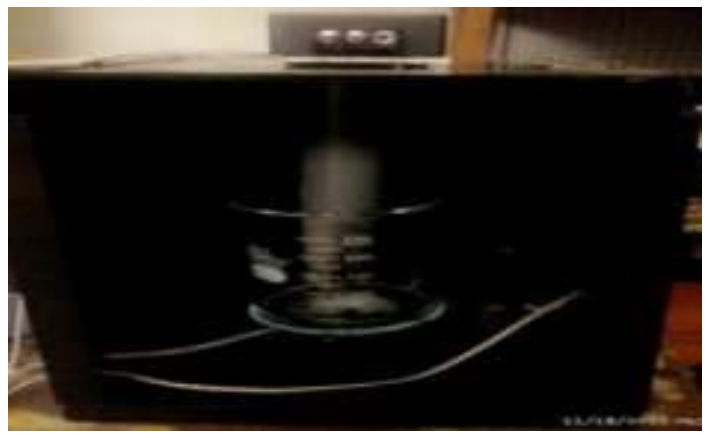

Gambar 6. Foto desain kotak sampel

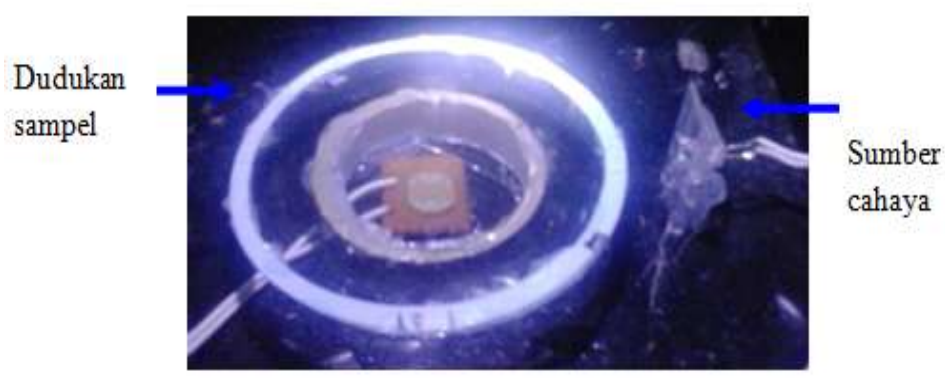

Gambar 7. Foto posisi sensor kekeruhan pada dasar kotak sampel 
Sensor LDR diletakkan dibawah meja sampel yang terbuat dari kaca dengan diameter $7,5 \mathrm{~cm}$, sedangkan sumber cahaya ada berada di samping gelas beker. Bagian kedua dari sistem alat ukur ini adalah box rangkaian. Box ini memiliki dimensi $25 \times 19 \times 8 \mathrm{~cm}$. bentuk box alat dapat dilihat pada Gambar 8 .

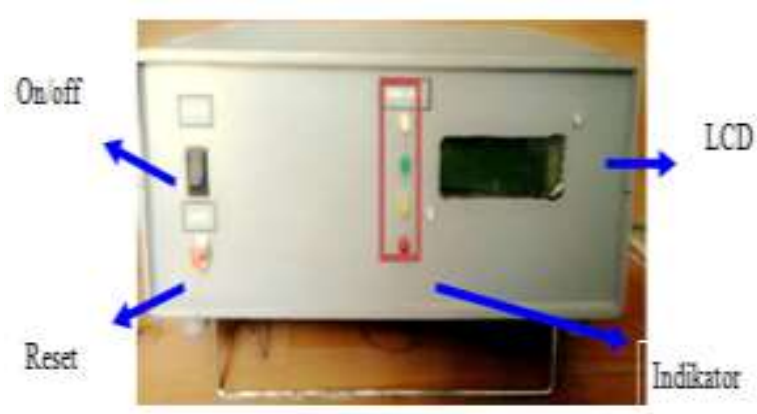

Gambar 8. Foto box rangkaian

Sistem pengukuran kadar salinitas dan kekeruhan ini dilengkapi dengan sistem input dan output. Sistem input memiliki dua tombol yang terletak pada sebelah kanan kotak rangkaian. Tombol tersebut adalah tombol on/off yang berfungsi untuk menghidupkan beserta mematikan sistem dan tombol reset yang berfungsi untuk mengembalikan mikrokontroler kesetting awal. Sistem output juga ada dua, yaitu LED sebagai indikator salinitas dan LCD yang terletak pada sebelah kiri atas dan berfungsi untuk menampilkan kadar salinitas dan kekeruhan air yang diuji.

Rangkaian elektronika pembangun alat ukur ditempatkan dalam box rangkaian. Hasil desain rangkaian elektronika sistem pembangun alat ukur salinitas dan kekeruhan air dapat dilihat pada Gambar 9.

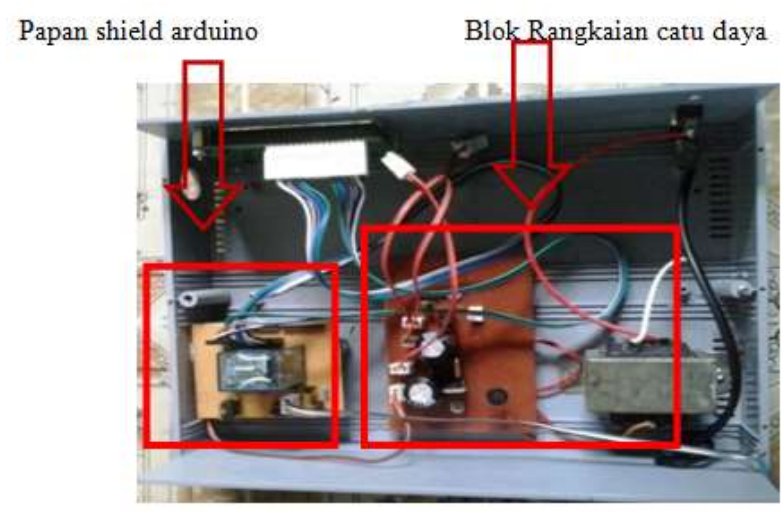

Gambar 9. Foto hasil desain rangkaian elektronika sistem alat ukur

Gambar 9 merupakan foto tampak atas box rangkaian. Pada gambar juga dapat dilihat bahwa rangkaian elektronika pembangun sistem ini terdiri dari beberapa bagian, yaitu catu daya, papan shield arduino, dan rangkaian LCD. Shield arduino dipasang parallel di atas papan Arduino uno328, shield arduino berupa modul yang berisi beberapa blok rangkaian. Blok 
rangkaian yang pertama yaitu sensor salinitas yang dimasukkan ke input analog A0 pada arduino. Blok rangkaian yang kedua yaitu sensor LDR yang dimasukkan ke input analog A1. Blok rangkaian yang ke tiga adalah blok rangkaian LCD yang terhubung ke pin 13, 12, $11,10,9$, dan 8 , dan blok rangkaian yang ke empat adalah LED inidkator yang terpasang pada output digital 2, 3, 4 dan 5 arduino.

Adapun bentuk keluaran hasil pengukuran kadar salinitas dan kekeruhan air dapat ditampilkan pada display LCD dan dapat dilihat pada Gambar 10.

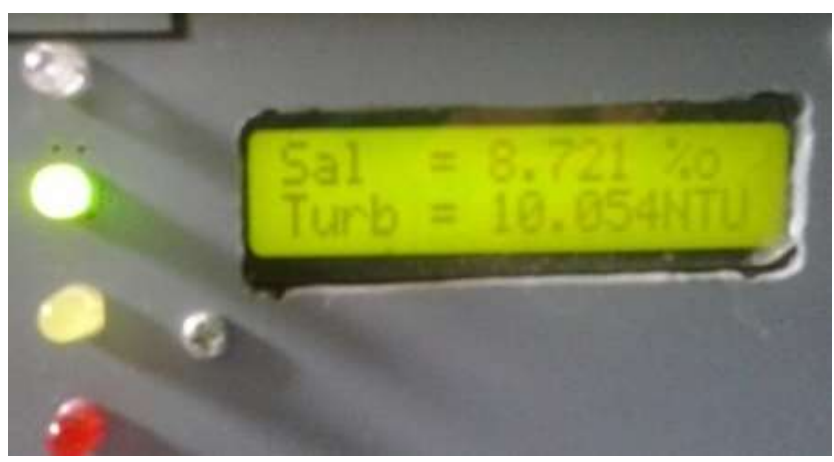

Gambar 10. Foto output salinitas dan kekeruhan

Dari gambar 10 dapat dililhat display LCD 16 x 2 pada alat ukur salinitas dan kekeruhan menampilkan kadar salinitas dan kekeruhan. Salinitas pada LCD disingkat dengan "Sal" dengan satuan $(\%$ o $)$ permil dan kekeruhan ditulis dengan "Turb" dengan satuan NTU. Pada gambar juga dapat dilihat LED yang menyala adalah LED hijau yaitu pada

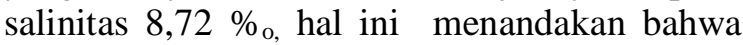

air sampel yang diuji termasuk dalam kategori air payau.

\section{Spesifikasi desain Sistem}

a. Hubungan tegangan keluaran sensor elektroda dengan kadar salinitas

Elektroda yang digunakan sebagai sensor adalah tembaga. Secara visual hubungan tegangan keluaran sensor elektroda dengan salinitas dapat dilihat pada Gambar 11.

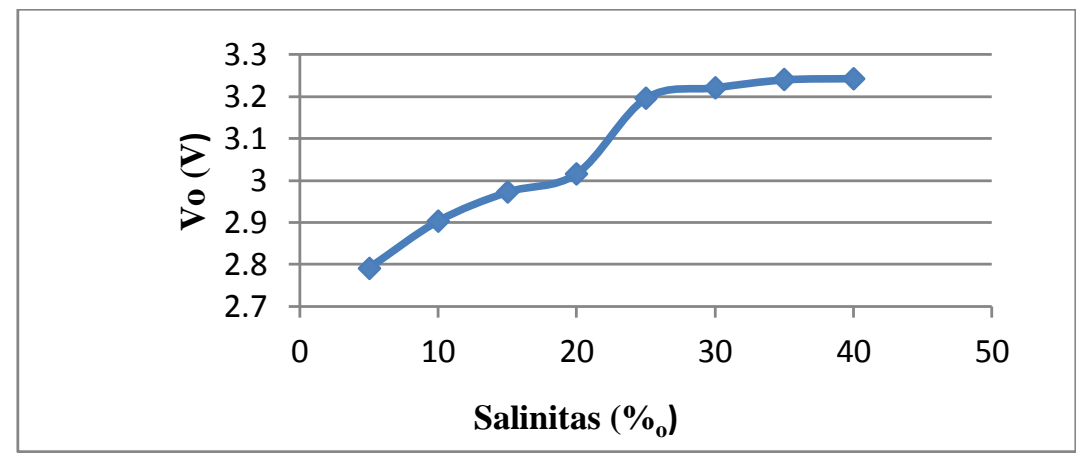

Gambar 11. Hubungan tegangan keluaran sensor elektroda dengan salinitas 
Semakin tinggi kadar sallinitas pada suatu larutan berarti semakin banyak ion bebasnya. Hal ini juga menunjukan kemampuan larutan untuk menghantarkan arus listrik semakin tinggi dan tegangan keluaran juga semakin bertambah. Pada Gambar 11 dapat dilihat tegangan keluaran sensor sebanding dengan kadar salinitas yaitu tegangan keluaran akan bertambah seiring bertambahnya kadar salinitas. Di antara titik keempat dan titik kelima pada grafik terdapat perbedaan tegangan keluaran yang cukup tinggi, hal ini dikarenakan jumlah ion yang bergerak cenderung tidak stabil. Pada grafik juga dapat diketahui bahwa tegangan keluaran sensor tertinggi yaitu mencapai $3,25 \mathrm{~V}$ pada salinitas $40 \%$ o dan terendah terjadi pada salinitas $5 \%$.

b. Hubungan tegangan keluaran sensor LDR dengan kekeruhan

LDR adalah sensor yang resistansinya dipengaruhi oleh jumlah cahaya yang jatuh pada permukaannya. Intesitas cahaya yang diterima LDR akan bervariasi seiring tingkat kekeruhan air yang diuji. Secara grafik, hubungan tegangan keluran sensor LDR dengan tingkat kekeruhan air dapat dilihat pada Gambar 12.

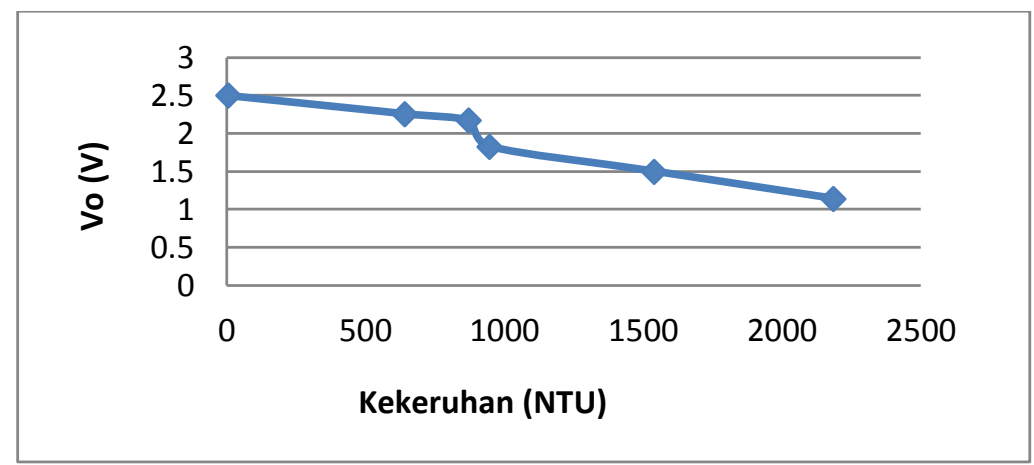

Gambar 12. Hubungan tegangan keluaran sensor LDR dengan kekeruhan

Gambar 12 merupakan grafik hubungan antara kadar kekeruhan air dengan tegangan keluaran sensor. Pada grafik dapat dilihat bahwa tegangan keluaran sensor LDR berbanding terbalik dengan tingkat kekeruhan air yaitu semakin tinggi tingkat kekeruhan maka tegangan keluaran sensor LDR semakin kecil. Pada grafik juga dapat diketahui bahwa tegangan keluaran sensor tertinggi yaitu mencapai 2,5 V pada kekeruhan 6,59 NTU yang dimiliki air berwarna ungu dan terendah pada kekeruhan tertinggi yaitu 2185 NTU oleh air berwarna putih. Selain itu terdapat dua titik yang berdekatan yaitu sampel berwarna merah dengan kekeruhan 870 dan hijau dengan kekeruhan 945. Hal ini juga menandakan bahwa daya tembus cahaya pada warna larutan berwarna merah dan hijau hampir sama.

c. Penentuan ketepatan sistem pengukuran salinitas

Ketepatan sensor salinitas dapat diperoleh dengan melakukan pengukuran terhadap kadar salinitas air menggunakan alat ukur dibuat (AUD) dan membandingkannya dengan pengukuran menggunakan alat ukur standar (AUS) Refraktometer. Melalui pengukuran ini didapatkan nilai rata-rata salinitas, persentase kesalahan (Err) dan persentase ketepatan seperti yang terdapat pada Tabel 1. 
Tabel 1. Ketepatan sistem pengukuran salinitas

\begin{tabular}{|c|c|c|c|c|c|}
\hline \multirow[t]{2}{*}{ Sampel } & \multicolumn{3}{|c|}{ Salinitas rata-rata $\left(\%_{0}\right)$} & \multirow[t]{2}{*}{$\begin{array}{l}\text { Err } \\
(\%)\end{array}$} & \multirow[t]{2}{*}{$\begin{array}{c}\text { Ketepatan } \\
(\%)\end{array}$} \\
\hline & AUS & AUD & LED & & \\
\hline A & 5 & 5,37 & Hijau & 7,44 & 92,56 \\
\hline B & 29 & 30,27 & Hijau & 4,38 & 95,61 \\
\hline $\mathrm{C}$ & 29 & 29,92 & Hijau & 3,20 & 96,79 \\
\hline $\mathrm{D}$ & 30 & 31,20 & Kuning & 4,01 & 95,99 \\
\hline $\mathrm{E}$ & 30 & 30,57 & Hijau & 1,92 & 98,07 \\
\hline $\mathrm{F}$ & 31 & 32,48 & Kuning & 4,77 & 95,22 \\
\hline \multicolumn{4}{|c|}{ Rata-rata } & 4,28 & 95,71 \\
\hline
\end{tabular}

Pada Tabel 1 dapat dilihat bahwa pengujian dilakukan pada enam sampel yang diberi label A, B, C, D, E dan F. Sampelsampel ini diambil dari beberapa tempat yang berbeda. Sampel A merupakan air sungai yang diambil di daerah kampung baru, Pesisir Selatan. Sampel B dan C memiliki salinitas sama merupakan sampel air laut yang diambil dari kecamatan Bungus dan pantai SMK kelautan Painan. Sampel D dan E diambil dari kawasan wisata pantai Padang dan Pantai Gajah. Selain itu sampel F merupakan sampel yang diambil dari pelabuhan pengasahan Painan, Pesisir Selatan.
Berdasarkan data pada tabel 1 dapat dilihat bahwa alat ukur salinitas memiliki persentase kesalahan (Err) yang cukup kecil yaitu mulai dari $1,92 \%$ sampai dengan $7,44 \%$. Kesalahan rata-rata pada sistem pengukuran salinitas ini adalah $4,28 \%$ dengan ketepatan rata-rata $95,71 \%$. Data ini dapat menunjukan bahwa alat ukur salinitas ini cukup baik untuk digunakan di Laboratorium ataupun lembagalembaga penelitian lainnya. Secara visual, plot ketepatan pengukuran salinitas menggunakan AUS Refraktometer dan menggunakan AUD dapat dilihat pada Gambar 13.

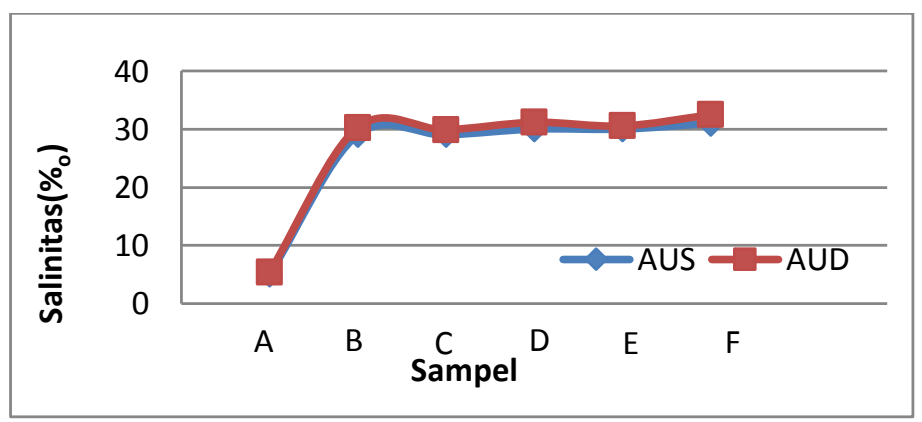

Gambar 13. Plot pengukuran salinitas menggunakan AUD dan AUS

Pada Gambar 13 dapat dilihat hampir semua hasil pengukuran salinitas menggunakan AUD mendekati hasil pengukuran menggunakan AUS. Pada Grafik juga dapat dilihat adanya perbedaan yang signifikan antara sampel pertama dengan beberapa sampel lainnya. Hal ini disebabkan sampel pertama tersebut diambil dari air sungai dengan salinitas 5 permil sedangan lima sampel berikutnya 
diambil dari air laut dengan salinitas rata-rata mencapai 30 permil.

d. Penentuan ketepatan sistem pengukuran kekeruhan

Penentuan ketepatan sensor kekeruhan dilakukan dengan melakukan pengukuran menggunakan AUD dan Sebagai pembanding, sampel terlebih dahulu diukur kadar kekeruhannya melalui uji laboratorium menggunakan AUS Turbiditymeter.
Pengukuran dilakukan terhadap sampel yang diberi label A, B, C dan D. Sampel dibuat dengan melarutkan $3 \mathrm{ml}$ pasta kedalam $300 \mathrm{ml}$ air bersih. Adapun Pasta pewarna yang digunakan adalah warna kuning, merah, hijau dan merah muda. Melalui pengukuran ini didapatkan nilai rata-rata, persentase kesalahan (Err) dan persentase ketepatan seperti yang terdapat pada Tabel 2.

Tabel 2. Ketepatan sistem pengukuran kekeruhan air

\begin{tabular}{|c|c|c|c|c|}
\hline \multirow{2}{*}{$\begin{array}{c}\text { Sampe } \\
1\end{array}$} & \multicolumn{2}{|c|}{$\begin{array}{l}\text { Salinitas rata- } \\
\text { rata }\left(\%_{0}\right)\end{array}$} & \multirow{2}{*}{$\begin{array}{l}\text { Err } \\
(\%)\end{array}$} & \multirow{2}{*}{$\begin{array}{c}\text { Ketepatan } \\
(\%)\end{array}$} \\
\hline & AUS & AUD & & \\
\hline A & 640 & 669,16 & 4,55 & 95,44 \\
\hline B & 870 & 831,36 & 4,44 & 95,55 \\
\hline $\mathrm{C}$ & 945 & 938,17 & 0,72 & 99,27 \\
\hline $\mathrm{D}$ & 1540 & $\begin{array}{c}1549,1 \\
4\end{array}$ & 5,25 & 94,74 \\
\hline \multicolumn{3}{|c|}{ Rata-rata } & 3,74 & 96,25 \\
\hline
\end{tabular}

Pada Tabel 2 dapat dilihat perbandingan antara AUS dengan AUD. Berdasarkan data tersebut juga dapat dilihat bahwa persentase kesalahan sistem kecil yaitu mulai dari 0,7\% sampai dengan $5,2 \%$. Kesalahan rata-rata pada sistem alat ini adalah 3,74\% dengan ketepatan rata-rata $96,25 \%$. Data ini menunjukan bahwa alat ukur kekeruhan ini cukup baik untuk digunakan di Laboratorium dan lembagalembaga penelitian lainnya. Selain itu, plot kedekatan nilai pengukuran kekeruhan menggunakan AUS dengan AUD dapat dilihat pada Gambar 14.

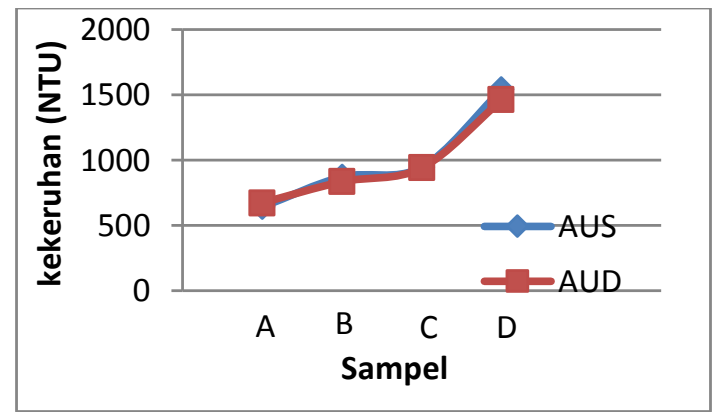

Gambar 14. Plot pengukuran kekeruhan menggunakan AUD dan AUS 
Gambar 14 memperlihatkan hasil pengukuran tingkat kekeruhan antara AUS dan AUD. Ada empat sampel yang diukur yaitu campuran air dengan pasta kuning dengan kekeruhan 640 NTU, campuran air dengan pasta merah yang memiliki kekeruhan 870 NTU, campuran pasta air dengan pasta hijau dengan kekeruhan 945 NTU dan kekeruhan 1540 NTU yang dimiliki oleh campuran air dengan pasta merah muda. Berdasarkan grafik juga dapat dilihat bahwa hasil pengukuran menggunakan AUD berdempet dan hampir mendekati hasil pengukuran menggunakan AUS.

e. Penentuan ketelitian sistem pengukuran salinitas

Penentuan ketelitian dapat diketahui dengan cara melakukan pengukuran berulang. Pengukuran kadar salinitas sebanyak 10 kali terhadap masing-masing sampel dengan tujuan untuk mendapatkan nilai rata-rata, ketelitian, standar deviasi $(\Delta \mathrm{X})$ dan persentase kesalahan relatif (KR). Berdasarkan data pengukuran berulang terhadap enam sampel diperoleh hasil seperti yang dapat dilihat pada Tabel 3 .

Tabel 3. Ketelitian sistem pengukuran salinitas

\begin{tabular}{ccccc}
\hline Sampel & $\bar{X}\left(\%_{\mathrm{o}}\right)$ & ketelitian & $\Delta \mathrm{X}$ & $\mathrm{KR}(\%)$ \\
\hline A & 5,372 & 0,982874 & 0,29643 & 2,51 \\
$\mathrm{~B}$ & 30,27 & 0,973507 & 0,60376 & 2,00 \\
$\mathrm{C}$ & 29,92 & 0,965347 & 0,47814 & 1,59 \\
$\mathrm{D}$ & 31,20 & 0,996058 & 0,41602 & 1,33 \\
$\mathrm{E}$ & 30,57 & 0,926840 & 0,64974 & 2,09 \\
F & 32,48 & 0,990764 & 0,68527 & 2,10 \\
\hline
\end{tabular}

Pada Tabel 3 dapat dilihat bahwa sistem alat ini memiki ketelitian yang cukup tinggi dengan rentang ketelitian mulai dari 0,926840 sampai dengan ketelitian tertinggi yaitu 0,996058. kesalahan pada sistem alat ini juga kecil yaitu mulai dari $1,33 \%$ sampai dengan $5,51 \%$.

f. Penentuan ketelitian sistem pengukuran kekeruahan
Penentuan ketelitian sistem pengukuran kekeruhan dapat diketahui dengan cara melakukan pengukuran berulang untuk masingmasing sampel sebanyak 10 kali. Berdasarkan hal tersebut dapat ditentukan nilai rata-rata, ketelitian, standar deviasi $(\Delta \mathrm{X})$, dan kesalahan relatif (KR). Berdasarkan data yang diperoleh dari pengukuran berulang terhadap kekeruhan dapat diperoleh hasil yang dapat lihat pada Tabel 4.

Tabel 4. Ketelitian sistem pengukuran kekeruhan

\begin{tabular}{ccrcc}
\hline Sampel & $\bar{X}(\mathrm{NTU})$ & ketelitian & $\Delta \mathrm{X}$ & $\mathrm{KR}(\%)$ \\
\hline A & 669,168 & 0,97016 & 3,58014 & 0,53 \\
B & 831,361 & 0,96641 & 5,52150 & 0,66 \\
C & 938,172 & 0,98997 & 2,81464 & 0,30 \\
D & 1459,14 & 0,98118 & 12,8721 & 0,88 \\
\hline
\end{tabular}

Tabel 4 merupakan data pengukuran berulang pada empat sampel yang diberi label A, B, C dan D. Pada tabel juga dapat dilihat bahwa alat ini memeiliki ketelitian yang cukup tinggi yaitu mulai dari 0,9664 dan sampai dengan ketelitian tertinggi yaitu mencapai 0,9811 .

Berdasarkan analisis data yang telah dilakukan dapat memberikan hasil penelitian 
yang sesuai dengan tujuan penelitian. Adapun hasil penelitian yang diperoleh yaitu spesifikasi desain dan performansi sistem, ketepatan dan ketelitian sistem pengukuran alat ukur salinitas dan kekeruhan.

Tujuan pembuatan alat ukur ini adalah untuk mengukur kadar salinitas dan tingkat kekeruhan air. Ada dua sensor yang digunakan yaitu elektroda dan LDR. Sensor elektroda digunakan untuk mengetahui kadar salinitas dan sensor LDR digunakan untuk mengetahui kekeruhan air. Kadar salinitas dalam air diketahui dengan mencelupkan elektroda kedalam air, dimana elektroda akan mengukur resistansi air yang kemudian dikonversi menjadi tegangan. Metode pengukuran kadar salinitas melalui resistansi ini biasa disebut dengan metode daya hantar listrik atau konduktivitas.

Pengukuran kekeruhan ditentukan melalui banyaknya cahaya yang diserap dan dipantulkan oleh partikel-partikel yang terdapat di dalam air. LDR akan menerima cahaya yang dipantulkan oleh partikel-partikel terlarut di dalam air. Sumber cahaya yang digunakan adalah LED yang diletakkan pada posisi $90^{\circ}$ terhadap LDR. Kekeruhan air yang berbeda menyebabkan resistansi LDR berubah. Perubahan ini akan dikonversi ke dalam tegangan dan akan diolah pada mikrokontroler.

Alat ini menggunakan Mikrokontroler Arduino uno328 yang akan mengolah data dari sensor, hasil pengukuran akan ditampilkan dalam dua output yaitu LED indikator dan LCD. LED indikator untuk mengetahui rentangan kadar salinitas yaitu air bersih dengan salinitas kecil dari $0,5 \%$, air payau dengan salinitas $0,5-30 \%$ o, air laut dengan salinitas 31$50 \%$ o dan air pahit dengan salinitas besar dari $50 \%$. Selain itu LCD digunakan untuk menampilkan data kadar salinitas dalam satuan permil $\left(\%_{0}\right)$ dan tingkat kekeruhan dalam satuan NTU.

Pengujian terhadap alat ukur salinitas dan kekeruhan air menggunakan sensor elektroda dan LDR ini dilakukan dengan membandingkan hasil pengukurannya dengan hasil pengukuran alat ukur standar yaitu Refraktometer dan Turbiditymeter. Proses pengujian ini dilakukan di Laboratorium Elektronika Instrumentasi dan di Dinas kesehatan Propinsi Sumatera Barat UPTD Balai Laboratorium Kesehatan .
Dilihat dari spesifikasi desain alat ukur ini, pada pengukuran salinitas diperoleh ketepatan dan ketelitian yang cukup tinggi yaitu ketepatan rata-rata $95,71 \%$ dan ketelitian ratarata $97,22 \%$ dengan kesalahan rata-rata $4,28 \%$ dan kesalahan relatif rata-rata 2,44\%. Pada pengukuran kekeruhan memiliki ketepatan dan ketelitian yang cukup tinggi. Ketepatan rata-rata mencapai $96,25 \%$, ketelitian rata $97,69 \%$ dan kesalahan relatif rata-rata $0,59 \%$. Berdasarkan data ini, dapat dikatakan bahwa alat ini bisa digunakan untuk mengukur kekeruhan air pada Lembaga penelitian, laboratorium dan sebagainya..

Ada beberapa kendala pada penelitian ini, yaitu efek elektrolisis pada larutan dan pengukuran yang menyimpang pada salnitas diatas $40 \%$. Elektrolisis terjadi apabila larutan dialiri arus listrik dimana elektrolisis semakin banyak terjadi seiring bertambahnya waktu elektroda di dalam air, hal ini menyebabkan tegangan keluaran sensor elektroda selalu berubah-berubah seiring bertambahnya waktu pengukuran. Kendala lain yang terjadi yaitu pada pengukuran kekeruhan, tegangan keluaran sensor juga berubah terhadap posisi gelas beker dan kondisi cahaya luar dan perlu waktu yang lama untuk mencari posisi yang pas agar hasil pengukuran mendekati hasil alat ukur standar Turbiditymeter.

Efek elektrolisis pada laarutan diatasi dengan menetapkan waktu penggukuran sampel selama satu menit dan agar hasil pengukuran tidak jauh menyimpang, maka pengukuran hanya dilakukan pada range yang mampu dicapai sensor yaitu dari salinitas $5 \%$ o sampai dengan salinitas $40 \%_{0}$. Selain itu, alat ini dilengkapi dengan LED indikator yang efisien dalam menunjukan rentang salinitas yang telah ditentukan. Pada pengukuran kekeruhan, kotak sampel dibuat tertutup untuk mengurangi pengaruh cahaya luar. Ada beberapa kelebihan sistem alat ukur ini yaitu menciptakan alat ukur kadar salinitas dan kekeruhan dengan alternatif yang lebih murah. Selain itu pada pengukuran kadar salinitas, mampu menciptakan alat ukur salinitas secara digital yang dalam penggunaannya tidak lagi bergantung kepada cahaya.

Pada peneliti selanjutnya, diharapkan agar membuat konstruksi dan jenis elektroda dengan bahan yang lebih baik dari tembaga, 
seperti kawat nikrom. Selain itu pada dudukan sampel dibuat meja tetap yang pas dengan ukuran gels beker.

\section{KESIMPULAN DAN SARAN}

Berdasarkan hasil pengujian dan analisis data serta pembahasan terhadap sistem alat ukur salinitas dan kekeruhan menggunakan sensor elektroda dan LDR dapat dirumuskan beberapa kesimpulan sebagai berikut:

1. Hasil spesifikasi performansi sistem alat ukur kadar salinitas dan kekeruhan ini terdiri kotak sampel dan box yang berisi seluruh rangkaian elektronika pembangun sistem. Rangkaian elektronika pembangun sistem ini terdiri dari catu daya teregulasi dan shield arduino yang berisi modul sensor dan LCD. Kotak sampel memiliki ukuran $15 \mathrm{x}$ $26 \times 25 \mathrm{~cm}$. pada bagian atas kotak dilubangi dengan diameter $4 \mathrm{~cm}$ sebagai tempat sensor elektroda, dan pada bagian dasar kotak terdapat dudukan sampel yang dibawahnya terpasang sensor LDR. Rentang salinitas dapat dilihat pada LED indikator dan pada LCD dapat juga ditampilkan kadar salinitas dan kekeruhan.

2. Karakteristik elektroda tembaga sebagai sensor salinitas yaitu semakin tinggi kadar salinitas sampel yang diukur, maka tegangan keluaran sensor elektroda juga semakin besar. Karakteristik LDR sebagai sensor kekeruhan yaitu semakin tinggi kadar kekeruhan air yang diukur, maka tegangan keluaran sensor semakin kecil

3. Ketepaan dari sistem pengukuran salinitas cukup rendah yaitu untuk hasil pengukuran kadar salinitas air memiliki ketepatan relatif rata-rata 95,71 \% dengan persentase kesalahan rata-rata $4,28 \%$.

4. Ketepaan dari sistem pengukuran kekeruhan cukup tinggi yaitu ketepatan relatif rata-rata $96,25 \%$ dengan persentase kesalahan ratarata $3,74 \%$.
5. Ketelitian sisem pengukuran kadar salinitas cukup tinggi dengan ketelitian rata-rata 0,9722 , standar deviasi rata rata 0,5206 dan kesalahan relatif rata-rata $2,44 \%$.

6. Ketelitian sistem pengukuran kekeruhan cukup tinggi dengan ketelitian rata-rata 0,9769 , standar deviasi rata-rata 6,1791 dan kesalahan relatif rata-rata 59,53.

Berdasarkan pembahasan yang telah dipaparkan, maka sebagai saran dalam tindak lanjut pengembangan penelitian tentang sistem ini adalah:

1. Perlu pengkajian lebih lanjut untuk menggunakan sensor lain yang mampu mendeteksi suatu bahan atau unsur dalam suatu larutan dengan harapan mampu menghasilkan spesifikasi sensor yang lebih baik, karena bahan sensor mempengaruhi tegangan keluaran sensor.

2. Desain mekanik dudukan sampel pada pengukuran kekeruhan perlu diperbaiki lagi agar posisi dudukan selalu tetap dan mampu menghasilkan pengukuran kekeruhan air yang cukup akurat.

\section{DAFTAR KEPUSTAKAAN}

HAACH Company. 2008. Portable Turbiditymeter Instrument and Manual. China: HAACH

Lewis, Edward Lyn. 1980. "The Practical Salinity Scale 1978 and its Antencedents". Journal of Oceanic Engineering, Vol Oe5, no. 1, january 1980.

Radiometer Analytical. 2004. Conductivity Theory and Practice. France : Radiometer Analytical SAS.

Republik Indonesia. 1990. PERMENKES No. 416 Tahun 1990 Tentang Syarat-Syarat Pengawasan Kualitas air. Jakarta : Menteri Kesehatan Republik Indonesia.

Shirley, Sarah. 2005. Assessments of Seven Refractometers for Evaluating Wildland Fire Retardants. U.S :Departement of Agriculture 